\title{
Reliability Model Construction for Complex System Based on Common Cause Failure Network
}

\author{
Lijie Li, ${ }^{1,2,3}$ Limin Jia, ${ }^{1,2,3}$ and Yanhui Wang ${ }^{1,2,3}$ \\ ${ }^{1}$ School of Traffic Transportation, Beijing Jiaotong University, Beijing 100044, China \\ ${ }^{2}$ State Key Laboratory of Railway Traffic Control \& Safety, Beijing Jiaotong University, Beijing 100044, China \\ ${ }^{3}$ Beijing Research Center of Urban Traffic Information Sensing and Service Technologies, Beijing Jiaotong University, \\ Beijing 100044, China \\ Correspondence should be addressed to Limin Jia; lmjia@bjtu.edu.cn
}

Received 29 July 2014; Revised 24 November 2014; Accepted 24 November 2014; Published 10 December 2014

Academic Editor: Shu-Ching Chen

Copyright ( 2014 Lijie Li et al. This is an open access article distributed under the Creative Commons Attribution License, which permits unrestricted use, distribution, and reproduction in any medium, provided the original work is properly cited.

\begin{abstract}
A new construction method of system reliability was proposed in this paper based on network and relevant failure. Taking the component units as the nodes and the interaction relationships between the nodes as the side lines, a new directional network reliability model with certain network topology characteristics was constructed. It can indicate the complex topology relationship, interaction mechanism, and the transmission mechanism of failure affect between mechanical integration and electrical integration of system components. Compared with the traditional research methods, the relevant failure was considered during this process. Through the application of the fault data in the bogie system of high-speed train, it was shown that a new network reliability model which considered the relevant failure can be constructed by the method proposed in this paper and the result can be more accurate, especially for the complex mechanical and electrical integration systems.
\end{abstract}

\section{Introduction}

Reliability study initially was developed from the reliability analysis of electronic components during World War II. From the beginning of the 1960s, reliability study was gradually expanded from a single reliability analysis of electronic component to the reliability of the general system [1-3]. As a special kind of systems, the earliest research about the reliability of network system focused on the field of communication networks. After the 1990s, along with the process of human social networking, network system reliability has become a hot research area, whose research objects extended from the communications network to the electricity network, transport network, logistics network, and so on [4-6].

The mechanism of high-speed train system is quite complex, and the coupling feature between components is strong. The relationship roles between components include mechanical effects, electrical effects, and information effects. Besides, the sensitivity between system elements is of a high degree. Any small change could cause the safe behavior of the entire system to rapidly deteriorate. However, the traditional analytical methods of its reliability, such as fault tree analysis [7], the chart of causality [8], the reliability block diagram [9], Markov process [10], Petri network [11], often assume that the components of the system are independent and the failure rate is exponentially distributed, which did not consider the relationship between the components. However, "relevance" is a common feature of mechanical system failures. If the system failure correlation was ignored and the assumption that the various components of system failure are independent was conducted, large errors or even wrong conclusions will reach during the process of system reliability analysis and calculation [12-15].

One single component failure in high-speed train system may lead to another or more system components failure, which may be caused by space, environment, design, or human factors, which can be called as relevant failure. It can be divided into two types, one is caused by the outside factors, such as lightning which lead to electronic equipment failure, and the other is caused by a single shared component failure, 
which is mainly researched in this paper and always called as common cause failure (CCF).

A new construction method of system reliability was proposed in this paper based on common cause failure network. It can indicate the complex topology relationship, interaction mechanism, and the transmission mechanism of failure affect between mechanical integration and electrical integration of system components. It also provided a common cause failure reliability model as the research basis for the complex system safety assessment and analysis.

\section{An Overview of Common Cause Failure}

The common cause failure (CCF) event in high-speed train system is the result of simultaneous failure of two or more individual components failure due to a single shared cause. For example, carriage wheel failure may lead to other components failure of the high-speed trains.

The alpha factor model estimates the CCF frequencies from a set of ratios of failures and the total component failure rate. The parameters of the model are as follows:

$Q_{T}$ : total failure probability of each component (including independent and common cause events);

$\alpha_{k}^{(m)}$ : fraction of the total probability of failure events that occur in the system involving the failure of $k$ components in a system of $m$ components due to a common cause.

The CCF basic event equation for any $k$ out of $m$ components failing in case of staggered testing is given by Wierman et al. [16]:

$$
Q_{\mathrm{CCF}}=Q_{T} \sum_{i=k}^{m}\left(\frac{m}{i}\right) \alpha_{i}^{(m)},
$$

where $\alpha_{i}^{(m)}$ is the ratio of $i$ and only $i$ CCF failures to total failures in a system of $m$ components, $m$ is the number of total components in the component group, $k$ is the failure criteria for a number of component failures in the component group, $Q_{T}$ is the random failure probability (total), and $Q_{C C F}$ is the failure probability of $k$ and greater than $k$ components due to CCF.

Define $Z_{j}^{j}$ individual failure events, $1 \leq j \leq m$, $Z_{l_{j}-n_{j}-o_{j}-p_{j}-\ldots}^{j}$, and several components simultaneous failure events, $0 \leq j \leq m$.

\section{Construction Method of System Reliability Model}

3.1. Research Assumption. This study involved the following assumptions:

(1) the topology of the system is always unchanged;

(2) exclude the impact from nonsystem components;

(3) components failure rate is exponentially distributed;
(4) subsystems or systems failures are immediately repaired and the distribution of lifetime after repair is the same as the original;

(5) there are two states for the components, subsystems, or systems: normal and failure and the failure are unrepeatable elements.

3.2. The Formal Expression of System's Connections. In complex mechatronic systems, the topological relationships between the components and the interaction mechanism can be revealed by the connection types and impact direction between the components. In this way, the formalized expression of relevant attributes for the key components of system corresponding to the network and a clear expression of the topology of the network can be formed and embed the components properties.

(1) The Connection Types between Components. There are three categories of connection types between components. The specific connections are as follows.

(i) Mechanical Connection. Mechanical connection is that the device elements can be connected by using mechanical fasteners in the system. This connection can be divided into removable connections and nonremovable connections. Removable connections include bolt connection, studs connection, screw connection, screw fastening, and pins connections. Nonremovable connections include riveting, welding, and bonding.

(ii) Electrical Connections. Electrical connections are all the connection types among different conductors inside the product. Electrical equipment mainly includes generators, transformers, busbars, circuit breakers, isolator, lines, and sensors.

(iii) Information Link. Information link refers to transferring the command or status information from one component to another component via some transmission medium. Transmission media can be divided into wired and wireless media. Information connections include information sending and information receiving.

(2) Impact Direction. The impact directions of the components are expressed as follows.

(i) One-Way Causality. The relationship between the system components creates one-way causality. For instance, if the relationship between component $\mathrm{A}$ and component $\mathrm{B}$ is oneway causality, then the state change of component A will directly lead to the state change of component $\mathrm{B}$, but the state of component B cannot affect the status of component A, which is represented by a one-way arrow.

(ii) Mutual Causality. The relationship between the system components creates mutual causality. For instance, if the relationship between component $\mathrm{A}$ and component $\mathrm{B}$ is mutual causality, then the state change of component A will directly lead to the state change of component $\mathrm{B}$, and the state 


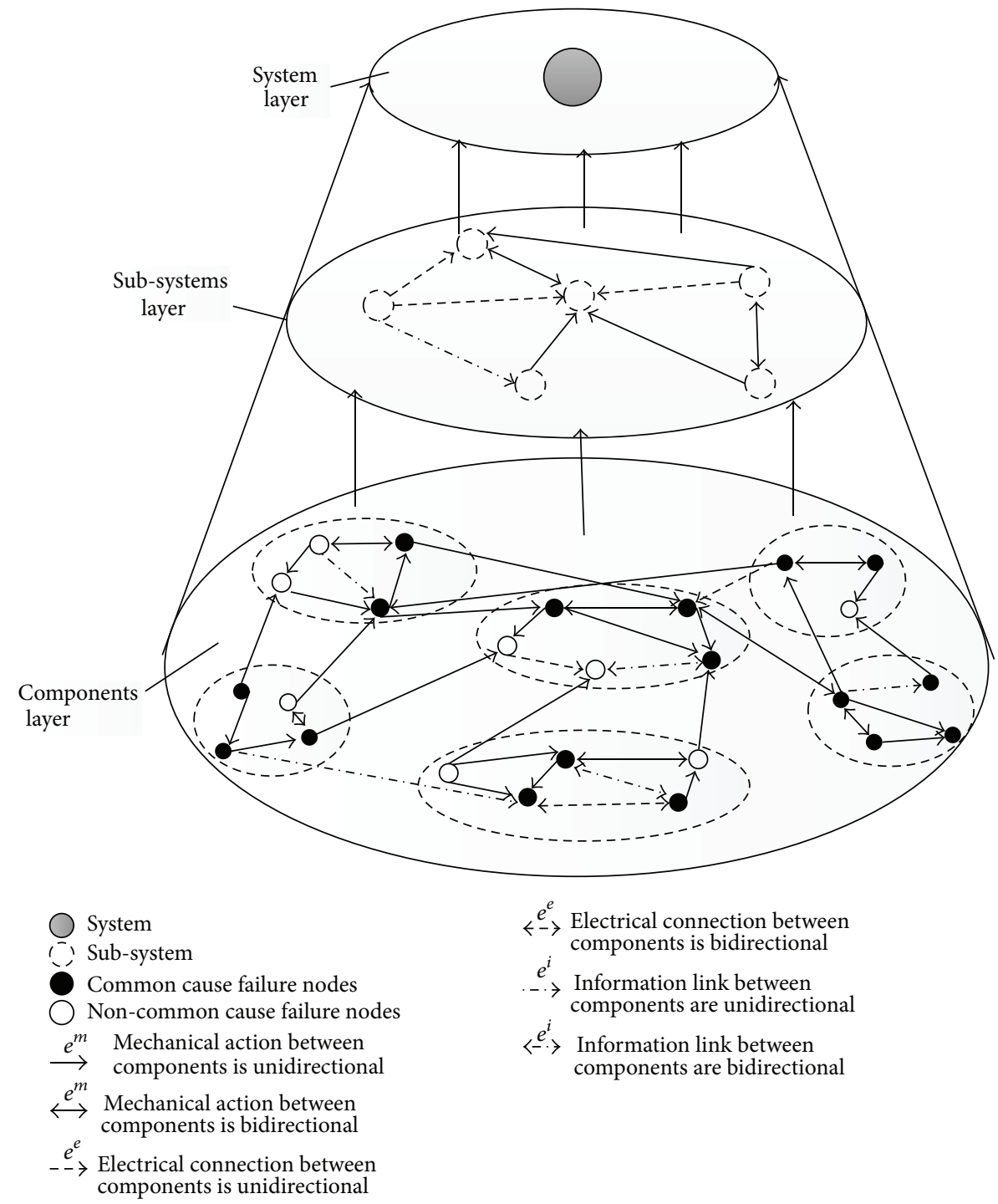

FIGURE 1: System reliability model.

of component B affects the status of component A, which is represented by a double arrow.

According to the connection types and the impact direction between components, the formal expression of system's connections can be shown in Table 1 .

\subsection{Construction of the Reliability Network Model}

(1) Construction of the Model for Subsystem. The subsystem consists of a series of components, which cannot be subdivided. Taking the components as the nodes and taking the roles of the relationship between the components as edges, the weighted network model was built, which has some characteristics of the network topology: $G_{i}=(v, e, r)$. The explanation is as follows:

$v$ : the collection of nodes, $v\left(G_{i}\right)=\left\{v_{i 1}, v_{i 2}, \ldots, v_{i n}\right\}$;

$e$ : the set of edges, $e\left(G_{i}\right)=\left\{e^{m}, e^{e}, e^{i}\right\}$; $r$ : the reliability of the nodes, $r_{i s}(t)(i=1,2, \ldots, n ; s=$ $1,2, \ldots, m)$, which means the reliability of component $s$ in subsystem $Q_{i}$ when the time is $t$.

(2) Construction of the Model for Complex System. The system consists of a series of subsystems. Taking the subsystems as the nodes and taking the roles of the relationship between the subsystems as edges, the weighted network model was built, which has some characteristics of the network topology: $G=$ $(V, E, R)$. The explanation is as follows:

$V$ : the collection of nodes, $V(G)=\left\{G_{1}, G_{2}, \ldots, G_{n}\right\}$;

$E$ : the set of edges, $E(G)=\left\{E^{m}, E^{e}, E^{i}\right\}$;

$R$ : the reliability of the nodes, $R(t)=\left\{R_{1}(t), R_{2}(t), \ldots\right.$, $\left.R_{n}(t)\right\}, R_{i}(t)(i=1,2, \ldots, n)$. Among them, $i$ is signed as subsystem, as shown in Figure 1. 
TABLE 1: The formal expression of system's connections.

\begin{tabular}{lcl}
\hline $\begin{array}{l}\text { Connection types between } \\
\text { components }\end{array}$ & Graphical representation & Description \\
\hline $\begin{array}{l}\text { Mechanical connection } \\
\left(e^{m}\right)\end{array}$ & Mechanical connection between components is unidirectional \\
\hline $\begin{array}{l}\text { Electrical connection } \\
\left(e^{e}\right)\end{array}$ & Mechanical connection between components is bidirectional \\
\hline $\begin{array}{l}\text { Information link } \\
\left(e^{i}\right)\end{array}$ & $0<e^{m}$ & Electrical connection between components is unidirectional \\
\hline
\end{tabular}

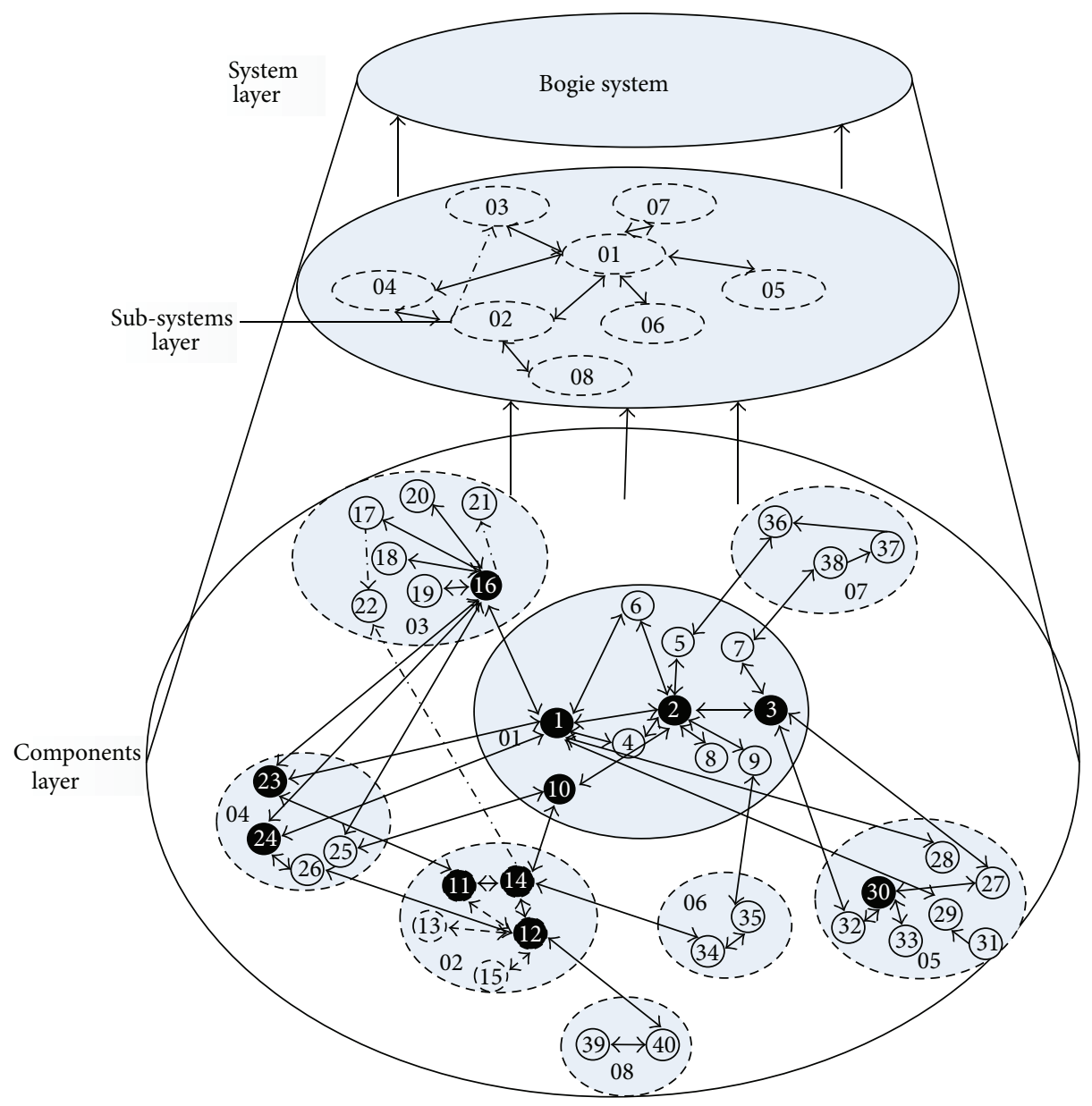

FIGURE 2: High-speed train bogie system reliability model.

\section{Application and Verification}

4.1. Example Overview. The bogie system of high-speed train was taken as the engineering background, which is a typical high-tech integrated system. As shown in Table 2, it can be divided into framework subsystem, wheel pair's subsystem, axle boxes apparatus subsystem, the first suspension apparatus subsystem, the secondary suspension apparatus subsystem, traction drives subsystem, braking device subsystem, tread surface cleaning device subsystem, and so on.

4.2. Model Construction. Based on the modeling approach proposed in this paper, the reliability model of bogie system of high-speed train was constructed based on common cause failure network, as shown in Figure 2. 
TABLE 2: The components of high-speed train bogie system.

\begin{tabular}{|c|c|c|c|}
\hline Number & Subsystems & Number & Components \\
\hline \multirow{10}{*}{01} & \multirow{10}{*}{ Framework } & 1 & Side beams \\
\hline & & 2 & Crossbeam \\
\hline & & 3 & $\begin{array}{l}\text { Vertical support beams } \\
\text { connecting beam air } \\
\text { spring }\end{array}$ \\
\hline & & 4 & $\begin{array}{l}\text { Support beam of air } \\
\text { spring }\end{array}$ \\
\hline & & 5 & Brake bracket of roulette \\
\hline & & 6 & Positioning arm seat \\
\hline & & 7 & $\begin{array}{l}\text { The mounting base of } \\
\text { pressurized cylinder }\end{array}$ \\
\hline & & 8 & Vertical stopper \\
\hline & & 9 & $\begin{array}{l}\text { The motor hanging } \\
\text { brackets }\end{array}$ \\
\hline & & 10 & $\begin{array}{l}\text { Gear box hanging } \\
\text { brackets }\end{array}$ \\
\hline \multirow{5}{*}{02} & \multirow{5}{*}{ Wheel pairs } & 11 & The axles \\
\hline & & 12 & The wheels \\
\hline & & 13 & The brake disc \\
\hline & & 14 & The device of gears \\
\hline & & 15 & The bearing \\
\hline \multirow{7}{*}{03} & \multirow{7}{*}{$\begin{array}{l}\text { Axle boxes } \\
\text { apparatus }\end{array}$} & 16 & Axis box \\
\hline & & 17 & The front cover of axis \\
\hline & & 18 & The back cover of axis \\
\hline & & 19 & $\begin{array}{l}\text { The positioning node of } \\
\text { rubber elastic }\end{array}$ \\
\hline & & 20 & Bearing units \\
\hline & & 21 & $\begin{array}{l}\text { Bearing temperature } \\
\text { detectors }\end{array}$ \\
\hline & & 22 & Speed sensors \\
\hline \multirow{4}{*}{04} & \multirow{4}{*}{$\begin{array}{l}\text { The first } \\
\text { suspension } \\
\text { apparatus }\end{array}$} & 23 & $\begin{array}{l}\text { The spring device of axle } \\
\text { box }\end{array}$ \\
\hline & & 24 & $\begin{array}{l}\text { The vertical damper of } \\
\text { axle boxes }\end{array}$ \\
\hline & & 25 & $\begin{array}{l}\text { The positioning node of } \\
\text { rubber elastic }\end{array}$ \\
\hline & & 26 & $\begin{array}{l}\text { The arrangements for } \\
\text { lifting of wheels }\end{array}$ \\
\hline \multirow{7}{*}{05} & \multirow{7}{*}{$\begin{array}{l}\text { The secondary } \\
\text { suspension } \\
\text { apparatus }\end{array}$} & 27 & Lateral damper \\
\hline & & 28 & Antisnake damper \\
\hline & & 29 & Air spring device \\
\hline & & 30 & $\begin{array}{l}\text { The central traction } \\
\text { drawbars seat }\end{array}$ \\
\hline & & 31 & Height adjustment valve \\
\hline & & 32 & Transverse backstop \\
\hline & & 33 & Traction drawbars \\
\hline \multirow{2}{*}{06} & \multirow{2}{*}{ Traction drives } & 34 & Couplings \\
\hline & & 35 & The traction motor \\
\hline \multirow{3}{*}{07} & \multirow{3}{*}{ Braking device } & 36 & Brake callipers \\
\hline & & 37 & Piping systems \\
\hline & & 38 & Brake booster cylinder \\
\hline \multirow{2}{*}{08} & \multirow{2}{*}{$\begin{array}{l}\text { Tread surface } \\
\text { cleaning device }\end{array}$} & 39 & Air cylinder \\
\hline & & 40 & Grinding \\
\hline
\end{tabular}

TABLE 3: Statistics of common cause failure.

\begin{tabular}{lc}
\hline Failure & CCF \\
\hline 1 & $Z_{2-4-6-16-23-24-28-29}^{1}$ \\
2 & $Z_{1-3-5-6-8-9-10}^{2}$ \\
3 & $Z_{2-7-27-32}^{3}$ \\
10 & $Z_{2-14-25}^{10}$ \\
11 & $Z_{12-14-23}^{11}$ \\
12 & $Z_{13-14-15-40}^{12}$ \\
14 & $Z_{10-11-12-34}^{14}$ \\
16 & $Z_{1-17-18-19-20-23-24-25}^{16}$ \\
23 & $Z_{1-11-16}^{23}$ \\
24 & $Z_{1-16-26}^{24}$ \\
30 & $Z_{27-32-33}^{30}$ \\
\hline
\end{tabular}

\subsection{Reliability Evaluation Based on the Model Proposed}

(1) Statistics of Common Cause Failure. 209 pieces of highspeed train fault data are recorded during the period from April 2009 to April 2011, 206 pieces of which are the intact data and three pieces of incorrect data are caused by lowlevel errors. As the situation cannot be restored, three pieces of erroneous data can only be abandoned. The statistics of common cause failure analysis of high-speed train bogies system are shown in Table 3.

(2) Reliability Experiment and Evaluation. The reliability of individual components and common cause failure can be obtained by reliability laboratory experiment for forty components in Table 2 . The reliability can be calculated as follows:

$$
\lambda=\frac{c}{T} \times 100 \%,
$$

where $\lambda$ is the failure rate, $c$ is failure number during the statistical time, and $T$ is the statistical time.

Because the reliability degree of the components has the characters of exponential distribution in the bogie system of high-speed train, the reliability of components can be calculated according to the failure rate when the time is $t$ :

$$
r(t)=\exp \left(-\int_{0}^{t} \lambda(t) d t\right)=e^{-\lambda t} .
$$

The laboratory experiment of forty individual components can be finished when the working time is similar to the statistical example. Based on the above method, the reliability of individual components can be obtained and marked as $r(t)$.

Similarly, when the components with the relationship of common cause failure were connected with each other in their group, the reliability of eleven groups in Table 3 which have been proved to be with common cause failure also can be tested by laboratory experiment. Based on the test results, the corresponding reliability for each component can be corrected and marked as $r^{\prime}(t)$, which have considered the influence of common cause failure.

4.4. Verification. In order to verify the practical outcome of the construction and its corresponding evaluation method, 
TABLE 4: Comparison of reliability results.

\begin{tabular}{|c|c|c|c|}
\hline Number & $\begin{array}{c}\text { Reliability of } \\
\text { individual } \\
\text { components } \\
r(t)\end{array}$ & $\begin{array}{c}\text { Reliability } \\
\text { considering } \\
\text { common cause } \\
\text { failure } \\
r^{\prime}(t) \\
\end{array}$ & $\begin{array}{c}\text { Practical } \\
\text { reliability } \\
\quad r^{\prime \prime}(t)\end{array}$ \\
\hline 1 & 0.9999 & 0.9980 & 0.9981 \\
\hline 2 & 0.9999 & 0.9980 & 0.9975 \\
\hline 3 & 0.9999 & 0.9977 & 0.9980 \\
\hline 4 & 1 & 1 & 1 \\
\hline 5 & 0.9998 & 0.9983 & 0.9980 \\
\hline 6 & 0.9996 & 0.9910 & 0.9907 \\
\hline 7 & 0.9995 & 0.9935 & 0.9924 \\
\hline 8 & 0.9999 & 0.9959 & 0.9971 \\
\hline 9 & 0.9998 & 0.9937 & 0.9964 \\
\hline 10 & 0.9997 & 0.9915 & 0.9909 \\
\hline 11 & 0.9999 & 0.9896 & 0.9918 \\
\hline 12 & 0.9999 & 0.9926 & 0.9915 \\
\hline 13 & 0.9998 & 0.9950 & 0.9939 \\
\hline 14 & 0.9997 & 0.9991 & 0.9989 \\
\hline 15 & 0.9999 & 0.9999 & 0.9999 \\
\hline 16 & 0.9998 & 0.9990 & 0.9988 \\
\hline 17 & 1 & 0.9999 & 0.9998 \\
\hline 18 & 1 & 0.9997 & 0.9999 \\
\hline 19 & 0.9994 & 0.9943 & 0.9939 \\
\hline 20 & 0.9998 & 0.9953 & 0.9948 \\
\hline 21 & 0.9988 & 0.9988 & 0.9988 \\
\hline 22 & 0.9964 & 0.9964 & 0.9964 \\
\hline 23 & 0.9990 & 0.9943 & 0.9958 \\
\hline 24 & 0.9992 & 0.9946 & 0.9955 \\
\hline 25 & 0.9994 & 0.9923 & 0.9939 \\
\hline 26 & 0.9999 & 0.9953 & 0.9948 \\
\hline 27 & 0.9997 & 0.9969 & 0.9933 \\
\hline 28 & 0.9998 & 0.9907 & 0.9908 \\
\hline 29 & 0.9989 & 0.9923 & 0.9958 \\
\hline 30 & 0.9999 & 0.9999 & 0.9999 \\
\hline 31 & 0.9954 & 0.9954 & 0.9954 \\
\hline 32 & 0.9947 & 0.9953 & 0.9948 \\
\hline 33 & 0.9991 & 0.9969 & 0.9933 \\
\hline 34 & 0.9992 & 0.9959 & 0.9943 \\
\hline 35 & 0.9985 & 0.9985 & 0.9985 \\
\hline 36 & 0.9963 & 0.9963 & 0.9963 \\
\hline 37 & 0.9992 & 0.9992 & 0.9992 \\
\hline 38 & 0.9993 & 0.9993 & 0.9993 \\
\hline 39 & 0.9942 & 0.9942 & 0.9942 \\
\hline 40 & 0.9905 & 0.9905 & 0.9905 \\
\hline
\end{tabular}

the practical reliability results $r^{\prime \prime}(t)$ for each component obtained by the field test from April 2009 to April 2011 were compared with two cases in Table 4.
As shown in Table 4, after the correction of common cause failure, the reliability of each component is much more close to the practical reliability obtained by field test compared with the reliability of individual components. This rule is more obvious in the bolded data in Table 4. The effectiveness of the construction method proposed in this paper was verified.

\section{Conclusion}

This paper presents a new method to build the reliability model of system based on common cause failure network, which showed obvious advantages compared with the reliability of individual components. The main conclusions include the following.

(1) Taking the component units as the nodes and the interaction relationships between the nodes as the side lines, a new directional network reliability model with certain network topology characteristics was constructed. It can indicate the complex topology relationship, interaction mechanism, and the transmission mechanism of failure affect between mechanical integration and electrical integration of system components.

(2) Taking the bogie system of high-speed train as the engineering background, the reliability model considering common cause failure was constructed based on the method proposed in this paper. After application and verification, it showed to be much more accurate to the practical condition and the effectiveness of the method proposed in this paper was verified.

(3) The common cause failure network reliability model of the whole high-speed train can also be built in the same way. The subsequent research can focus on the analysis and safety assessment based on these reliability models, providing a new way to research safety problem for the high-speed train system and other complex systems.

\section{Conflict of Interests}

The authors declare that there is no conflict of interests regarding the publication of this paper.

\section{Acknowledgments}

The authors gratefully acknowledge the financial support of the Projects of National Science Support Plan of China (2011BAG01802), State Key Laboratory of Rail Traffic Control and Safety (RCS2014ZT23), and CRH3 High-Speed Train Fault Data Research (I11L00060).

\section{References}

[1] P. Taksakulvith, J. A. Jones, and L. Warrington, "An analysis of the drivers in the philosophy of reliability practice over the last 50 years," in Proceedings of the Annual Reliability and Maintainability Symposium, pp. 96-101, January 2004. 
[2] D. Beeckman, L. Schoonhoven, J. Fletcher et al., "EPUAP classification system for pressure ulcers: European reliability study," Journal of Advanced Nursing, vol. 60, no. 6, pp. 682-691, 2007.

[3] D. J. Viglione, A. C. Blume-Marcovici, H. L. Miller, L. Giromini, and G. Meyer, "An inter-rater reliability study for the rorschach performance assessment system," Journal of Personality Assessment, vol. 94, no. 6, pp. 607-612, 2012.

[4] J. Wu, D.-L. Duan, and J. Zhao, "Status and prospects on network reliability," Complex Systems and Complexity Science, vol. 8, no. 2, pp. 77-86, 2011.

[5] Y. Iida, "Basic concepts and future directions of road network reliability analysis," Journal of Advanced Transportation, vol. 33, no. 2, pp. 125-134, 1999.

[6] H. Boudali and J. B. Dugan, "A discrete-time Bayesian network reliability modeling and analysis framework," Reliability Engineering \& System Safety, vol. 87, no. 3, pp. 337-349, 2005.

[7] Y. Tao, D. Dong, and P. Ren, "Uncertainty analysis of system reliability estimate based on fault tree," Journal of Tongji University, vol. 38, no. 1, pp. 141-145, 2010.

[8] Q. Zhang, "Probabilistic reasoning based on dynamic causality trees/diagrams," Reliability Engineering and System Safety, vol. 4, no. 6, pp. 209-220, 1994.

[9] J.-Q. Liu, X.-G. Cui, B.-C. Sun, G.-G. Wang, D.-J. Jiang, and C. An, "Research on reliability of high voltage apparatus system of CRH3 electric multiple units," Journal of the China Railway Society, vol. 35, no. 6, pp. 22-27, 2013.

[10] J.-D. Liao, J.-B. Wu, and Z.-M. Liu, "Reliability analysis of a parallel repairable system based on Markovian arrival process," System Engineering Theory \& Practice, vol. 30, no. 6, pp. 10401046, 2010.

[11] S.-W. Jiang, W.-M. Lü, and H.-Y. Feng, "Reliability modeling and simulation of equipment system-of-systems based on timing Petri net," Systems Engineering and Electronics, vol. 35, no. 4, pp. 895-899, 2013.

[12] L. Xie, J. Zhou, and C. Hao, "System-level load-strength interference based reliability modeling of k-out-of-n system," Reliability Engineering and System Safety, vol. 84, no. 3, pp. 311-317, 2004.

[13] C.-S. Place, J.-E. Strutt, K. AIlsopp et al., "Reliability prediction of helicopter transmission systems using stress-strength interference with underlying damage accumulation," Quality and Reliability Engineering International, no. 15, pp. 69-78, 1999.

[14] G. Levitin, "Incorporating common-cause failures into nonrepairable multistate series-parallel system analysis," IEEE Transactions on Reliability, vol. 50, no. 4, pp. 380-388, 2001.

[15] L.-Y. Xie and W.-Q. Lin, "A discrete model for the prediction of common cause failure," Chinese Journal of Nuclear Science and Engineering, vol. 22, no. 2, pp. 186-192, 2002.

[16] E. T. Wierman, D. M. Rasmuson, and A. Mosleh, "Commoncause failure database and analysis system: event data collection, classification, and coding," NUREG/CR-6268, 2007. 

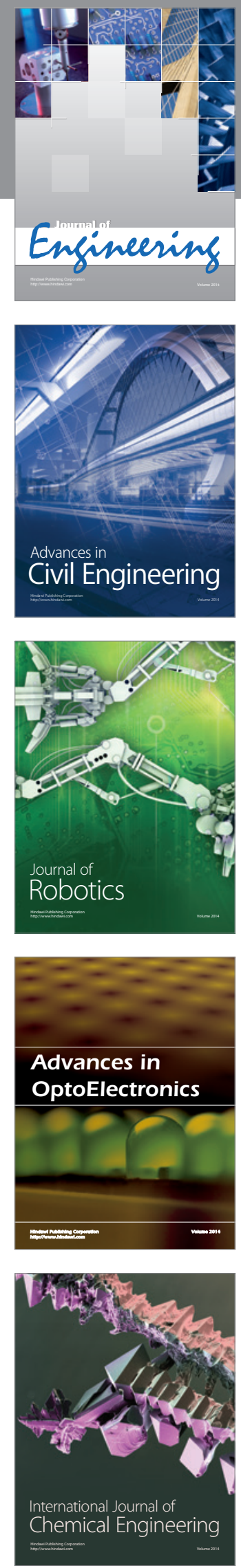

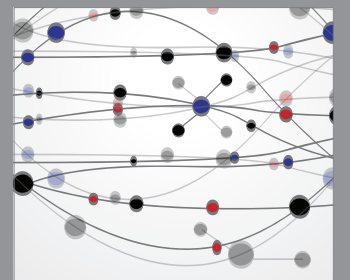

The Scientific World Journal
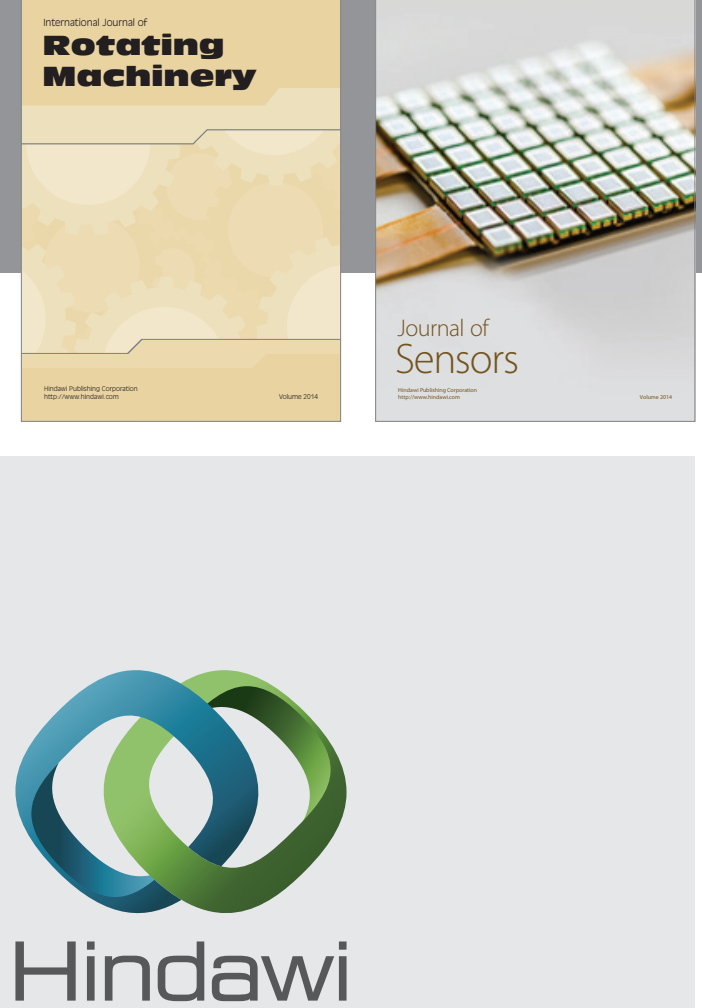

Submit your manuscripts at http://www.hindawi.com
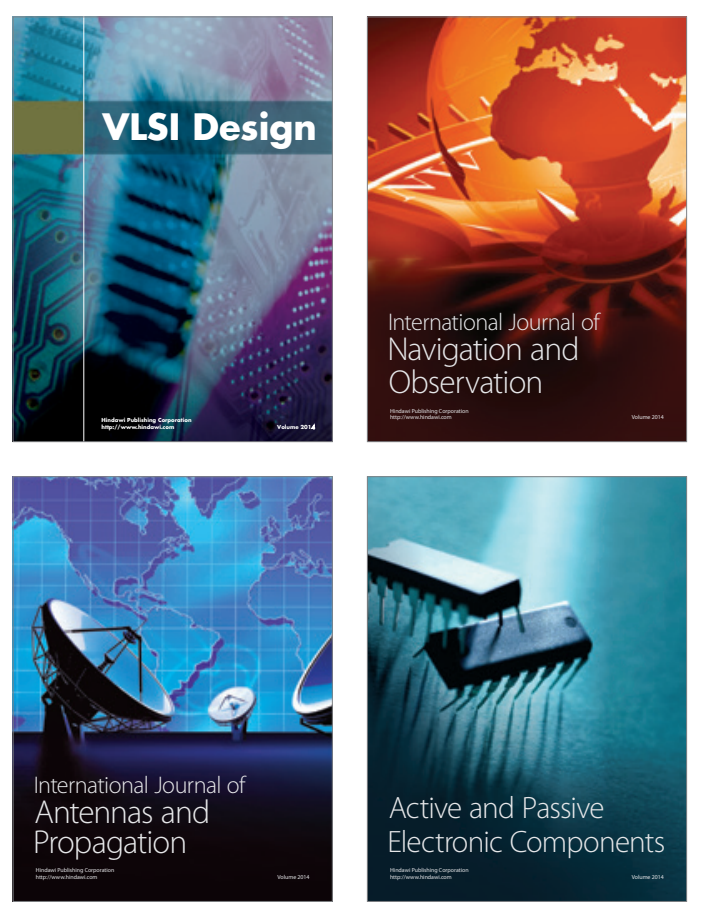
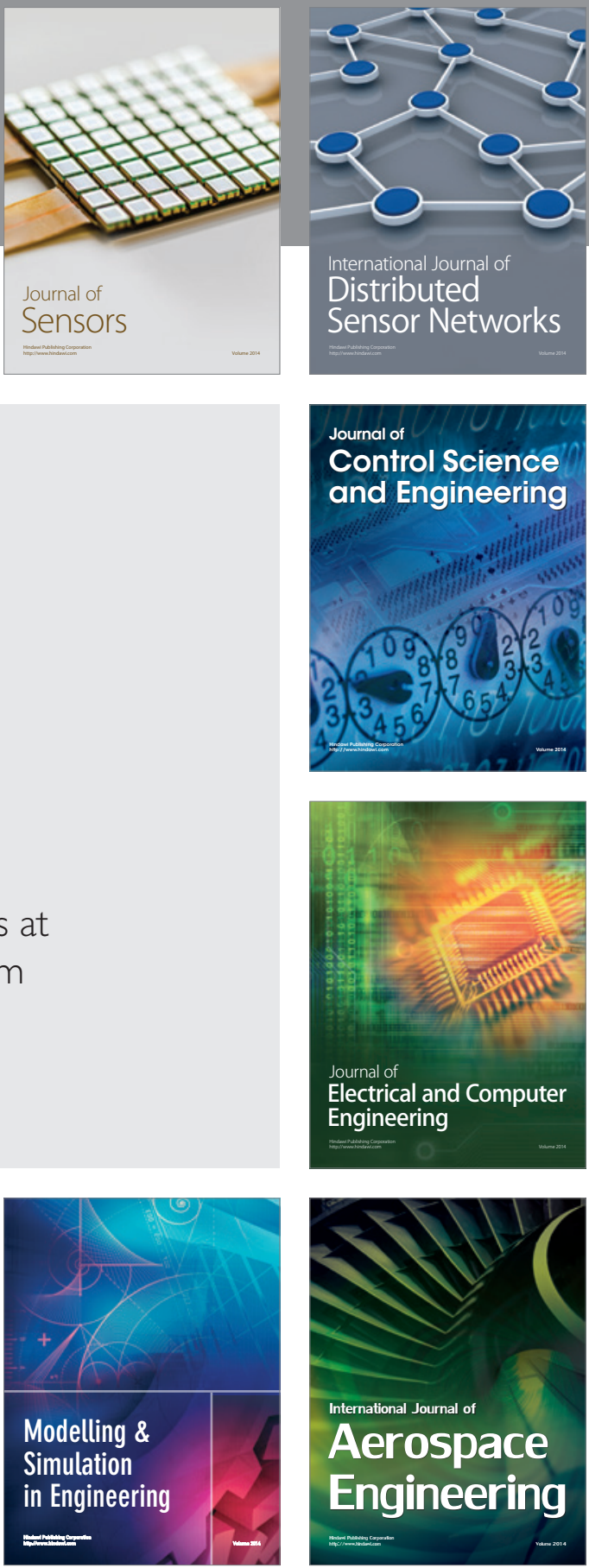

Journal of

Control Science

and Engineering
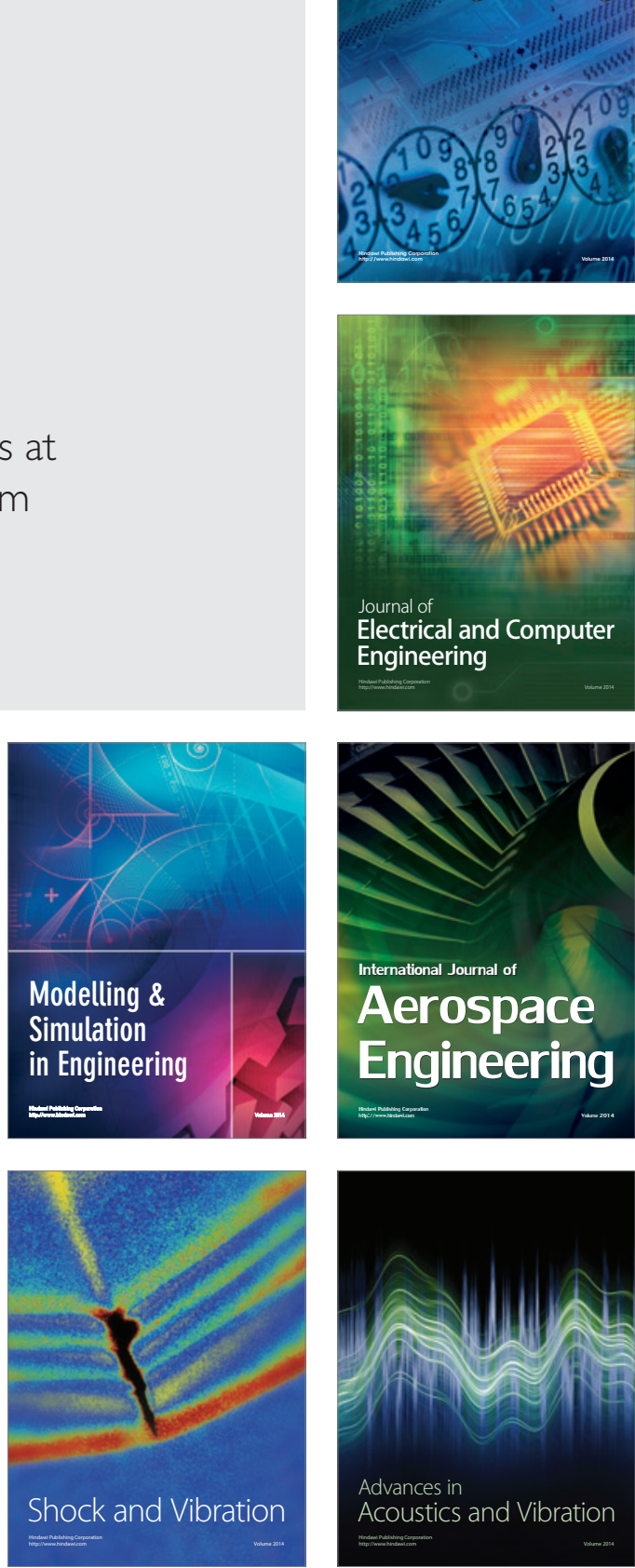